\title{
The Effect of Saline Gargling on Dry Mouth and Sore Throat in Patients with Thyroidectomy
}

\author{
Kim, Do Hui ${ }^{1} \cdot$ Park, Jeong Sook ${ }^{2}$ \\ ${ }^{1}$ Kyungpook National University Chillgok Hospital, Daegu; ${ }^{2}$ College of Nursing, Keimyung University, Daegu, Korea
}

Purpose: The purpose of this study was to investigate the effects of saline gargling on mouth dryness and sore throat for patients with thyroidectomy. Methods: A randomized controlled trial design was used with 53 participants assigned to either an intervention ( $\mathrm{n}=27$, saline gargling) or a control group ( $\mathrm{n}=26$, wet gauze). Pre-test dry mouth and sore throat were measured immediately after exiting the ward from OR. Post-test dry mouth and sore throat were measured at 1.50, 3.50, and 5.50 hours after exiting the ward from OR. Comprehensive sore throat was measured 24 hours after surgery. To analyze the data, $\chi^{2}$ test and independent $\mathrm{t}$-test were used. Results: Subjective dry mouth was lower in the experimental group than the control group $(t=-2.19, p=.033)$. There were no significant differences in the objective dry mouth and sore throat scores between the two groups. The comprehensive sore throat score was lower in the experimental group than the control group $(\mathrm{t}=-2.65, p=.011)$. Conclusion: Saline gargling is expected to be used as a nursing intervention method in patients undergoing thyroidectomy to alleviate the subjective dry mouth after 3.50 hours and sore throat after 5.50 hours and lasting 24 hours.

Key Words: Thyroid cancer, Saline solution, Xerostomia, Pain

\section{INTRODUCTION}

\section{Background}

Thyroid cancer is the most common malignant tumor that occurs in the endocrine system. In 2017, it ranked 4th and accounted for $11.3 \%$ of the total cancer incidence rate in Korea, and it has been reported that the incidence rate of thyroid cancer among women is $78.5 \%$, which is 3.3 times higher than that of $23.6 \%$ for men. ${ }^{1)}$ The most basic treatment for thyroid cancer is surgery, and total thyroidectomy or lobectomy can be performed depending on the stage of cancer. Due to general anesthesia performed during thyroidectomy, patients experience various discomforts such as thirst, sore throat, pain, nausea, vomiting, helplessness, or drowsiness. ${ }^{2)}$ Dry mouth and sore throat that occur after intubation for general anesthesia tend to be considered as minor complications compared to postoperative pain or vomiting, but they are discomforts that patients with thyroidectomy frequently complain of and some

\footnotetext{
*This manuscript is a condensed form of the first author's master's thesis from Keimyung University.

Address reprint requests to: Park, Jeong Sook College of Nursing, Keimyung University, 1095 Dalgubeol-daero, Dalseo-gu, Daegu 42601, Korea Tel: +82-53-258-7663 Fax:+82-53-580-3916 E-mail:jsp544@kmu.ac.kr Received:Sep 25, 2020 Revised: Nov 02, 2020 Accepted: Dec 15, 2020

This is an Open Access article distributed under the terms of the Creative Commons Attribution NoDerivs License. (http://creativecommons.org/licenses/by-nd/4.0/) If the original work is properly cited and retained without any modification or reproduction, it can be used and re-distributed in any format and medium.
}

people experience severe pain. ${ }^{3)}$

If glycopyrrolate, an anticholinergic agent, is used as a pre-anesthesia medication, it may dry the upper respiratory tract mucosa and cause damage during intubation. Also, it may cause dry mouth due to reduced salivation after surgery since the drug action time is long. ${ }^{4}$ In particular, many patients experience severe dry mouth while regaining consciousness due to prolonged oxygen supply and oral aspiration after surgery. ${ }^{5)}$ Meanwhile, $68.4 \%$ of thyroidectomy patients complained of sore throat due to endotracheal intubation ${ }^{6}$ and sore throat is the second most common side effect during postoperative anesthesia recovery. ${ }^{7)}$ Sore throat occurs due to local ischemia, swelling, and mucosal damage of the tracheal mucosa by the endotracheal tube and lasts from 1 to 2 days after surgery. ${ }^{3)}$ In particular, the incidence of sore throat is much higher with female patients than male patients. This is because women have a smaller tracheal diameter and the softer mucous membrane wall. ${ }^{899}$ The reason why patients undergoing thyroid cancer surgery complain more about sore throat than other general anesthesia patients is that the thyroid surgery position is adjacent to the endotracheal tube and its surrounding tissues are damaged during surgery.

As mentioned above, if dry mouth or sore throat is induced after thyroid cancer surgery, it can cause physiological and pathological changes together with various discomforts. If dry mouth occurs after surgery, a patient will experience discomfort when speaking, chewing and swallowing, or pain in the oral mucosa. In addition, oral buffering 
capacity and self-cleaning capacity are negatively affected and the pathogenicity of normal bacteria is increased, resulting in increased incidence of stomatitis, bad breath, dental caries, periodontal disease, and fungal infections. ${ }^{10)}$ In particular, a thyroid cancer patient suffers from various problems such as pain in the oral mucosa and stomatitis when the oral cavity becomes dry. And the capacity for eating is reduced, delaying recovery after surgery, making it difficult to follow the defined cancer treatment schedule, and resulting in additional costs. ${ }^{10)}$ In addition, if dry mouth is not properly managed, it may develop into stomatitis, periodontitis, etc., which may cause sepsis in a cancer patient whose resilience is weak. ${ }^{11)}$

The intervention used to relieve dry mouth and sore throat that occur after surgery include humidifier, ice, ${ }^{12)}$ wet gauze, ${ }^{13)}$ and gargling $^{5,10,11)}$ using various solutions. The wet gauze is just put on the lips, so its effectiveness in relieving dryness inside the oral cavity is limited. And there is a problem in that it is used in an inconsistent manner based on a nurse's personal experience and knowledge without a prescribed protocol. ${ }^{5)}$ Gargling is a nursing intervention to reduce the bacteria in an oral cavity and it can prevent upper respiratory tract infections as it has a cleaning effect by rinsing the mouth with a solution. ${ }^{12)}$ Cold water gargling was found to have a positive effect on reducing thirst, improving oral conditions, and reducing nausea in a surgery patient, ${ }^{2,9,13)}$ but it did not seem to have any effect on sore throat. Hydrous gargling was costly and inconvenient to use, and it has been pointed out that tantum and chlorhexidine solutions can affect the sensation of taste, stain teeth and tongue, and create an imbalance of normal cells in an oral cavity. ${ }^{14)}$

Meanwhile, saline is a colorless and odorless solution produced at the same concentration as the body fluid concentration and is widely used as an oral care solution because it is inexpensive and has no side effects. Saline has the effect of reducing swelling of the inflamed tissue in the neck and alleviating sore throat, and gargling with saline dilutes a large amount of mucus secretion to remove foreign substances such as allergens, bacteria, and microorganisms from the throat, reducing respiratory infection rates up to $40 \%{ }^{15)}$ In addition, a comparative study of the effects of saline, chlorhexidine, or tantum (benzydamine) showed no difference in terms of pathogens, incidence of stomatitis, and oral comfort. ${ }^{16)}$ Although a saline is partially used in clinical practice, it was difficult to find a case where systematic clinical trial studies were conducted on its effect on dry mouth and sore throat.

Therefore, this study sought to assess the effect of saline on dry mouth and sore throat with a cancer patient after general anesthesia thyroidectomy by performing gargling using a saline solution that is inexpensive, easy to get in a clinic, and easy to use.

\section{Purpose of study}

The purpose of this study was to examine the effect of saline gargling on dry mouth and sore throat with regard to a cancer patient who is fasting after thyroidectomy.

\section{Study Hypothesis}

- Hypothesis 1: The experimental group subjected to saline gargling will have a lower subjective dry mouth score after experimental treatment than the control group to which a wet gauze was applied.

- Hypothesis 2: The experimental group will show more dampness on a oral spill pad after the experimental treatment than the control group.

- Hypothesis 3: The experimental group will have a lower sore throat score than the control group.

Hypothesis 3-1: The experimental group will have a lower sore throat score after experimental treatment than the control group.

Hypothesis 3-2: The experimental group will have a lower overall sore throat score 24 hours after surgery than the control group.

\section{METHODS}

\section{Study Design}

This study is a randomized control group design to determine the effect of saline gargling on dry mouth and sore throat after surgery among female patients who underwent thyroidectomy under general anesthesia.

\section{Study Subjects}

The subjects were female patients aged 18 years or older who were hospitalized at Kyungpook National University Hospital in Daegu from March 12, 2018 to July 11, 2018 and met the following selection criteria. 1) Those who have been diagnosed with a form of thyroid cancer and have undergone total thyroidectomy or unilateral/bilateral subtotal resection. 2) Those who have undergone general anesthesia for more than 1 hour through endotracheal intubation. ${ }^{13)}$ 3) Those who maintained a fast for up to 6 hours after surgery. 4) Those who can read and respond to questionnaires. The criteria for exclusion included those with metastasis of thyroid cancer, those with dysphagia, and 
those who cannot goggle due to oral wounds or diseases, tooth-related problems, or mental illness.

Based on the effect size of a prior study, ${ }^{17)}$ which verified the effect of oral care using a saline solution on oral conditions, the two-sided test ttest was performed using the significance level $\alpha$ 는 .05, power $1-\beta=.80$, and effect size $\mathrm{d}=.80$. Based on the calculation result, 26 people were required for each group. By considering the dropout rate of $20 \%$, a total of 62 subjects were sampled: 31 for the experimental group and 31 for the control group.

First, 62 numbers were placed in random order in either set, i.e. 1 (experimental group) and 2 (control group), using Research Randomizer (Version 4.0), ${ }^{18)}$ a random allocation computer program. To confine the experimental treatment, 4 wards were also randomly allocated to be the experimental ward and the control ward, i.e. 1 (experimental group) and 2 (control), using a random allocation computer program. When a patient meeting the selection criteria was hospitalized, the patient was randomly allocated to the experimental group if the number previously assigned to the patient was 1 , and a patient was randomly allocated to the control group if the number previously assigned to the patient was 2. Four people from the experimental group were removed because they withdrew from the experiment and 5 from the control group were removed because they did not participate in the post survey. Therefore, the final number of study participants was 27 in the experimental group and 26 in the control group, a total of 53 (Figure 1). Regarding the assignment to the experimental group/control group, both the investigators and subjects were double-blinded without knowing anything about it.

\section{Measurements}

\section{1) Dry mouth}

(1) Subjective dry mouth: To measure mouth dryness during the post operative NPO period, Kim and Park's dry mouth measurement tool ${ }^{19)}$ was used. This tool was developed based on Thomson et al. ${ }^{20)}$ Fox et al. ${ }^{21)} \&$ Yarbro, Wujcik and Gobel ${ }^{22)}$ and was used with the permission of the tool developers. Kim and Park's dry mouth measurement tool ${ }^{19)}$ was supposed to ask the subjects to answer 'Yes' or 'No' with a total of 7 questions, but it was changed to a 5-point Likert scale format and composed of 0-4 points after collecting the opinions of the tool developers. The higher the score, the more severe is the dry mouth condition. In a study by Kim and Park, ${ }^{22)}$ Cronbach's a was .79, but in this study Cronbach's a was .71.
(2) Dampness on oral spill pad: As an objective measurement of dry mouth, the oral spill pad 1441-185 (WHATMAN, Kent, UK) was cut into $1 \mathrm{~cm}$ in width and $17 \mathrm{~cm}$ in length, and it was placed on the bottom of the mouth. And the subject was asked to close the mouth lightly. At this time, the tip of a oral spill pad is placed in contact with the wrinkle band of the tongue and should not touch the tongue if possible. After leaving it for 1 minute, it was taken out with a tweezer and the degree of dampness of the oral spill pad was measured and recorded on a scale of $\mathrm{mm}^{23)}$

\section{2) Sore throat}

(1) Sore throat score: This is a score measured by a sore throat number rating scale (NRS), which means that a subject reports how much the subject's throat pain is between 0 and 10 on a numerical scale. A subject marks a position corresponding to the intensity of the subject's own pain on the horizontal line where 'None (0)' is at the left end and 'Very severe (10)' is at the right end. The higher the score, the more severe is the sore throat.

(2) Overall sore throat score: The Oral Mucositis Daily Questionnaire (OMDQ) developed for cancer patients by Bellm et al. ${ }^{24)}$ was used. The OMDQ is a patient reporting tool that measures the degree of oral sore throat or limitation in daily activity. ${ }^{23)}$ Bellm et al. ${ }^{24)}$ included 2 diarrhea-related questions, but diarrhea-related questions were excluded in this study - as in the study by Choi and Kim. ${ }^{25)}$ Therefore, the questions in the tool used in this study included 1 question about overall health status, 1 question about the incidence frequency of oral sore throat, 5 questions about limitation in daily activity due to oral sore throat, and 1 question about oral sore throat intensity, a total of 8 questions. The higher the overall health score, the greater is the level of unhealthiness. The higher the score for oral sore throat and limitation in daily activity, the more severe are the symptoms. In the study by Choi and $\mathrm{Kim}^{25}$ for patients with acute leukemia, the reliability of this tool was Cronbach's a was .90 but the reliability in this study was Cronbach's a was .80.

\section{Study Procedure and Data Collection}

\section{1) Preparation}

First, a method of gargling with a saline solution was devised. After a thyroid cancer surgery operation is finished and a subject arrives at a hospital room, the upper body can be raised and the oxygen saturation is maintained at $95 \%$ or more. Using a tongue depressor, check if the 


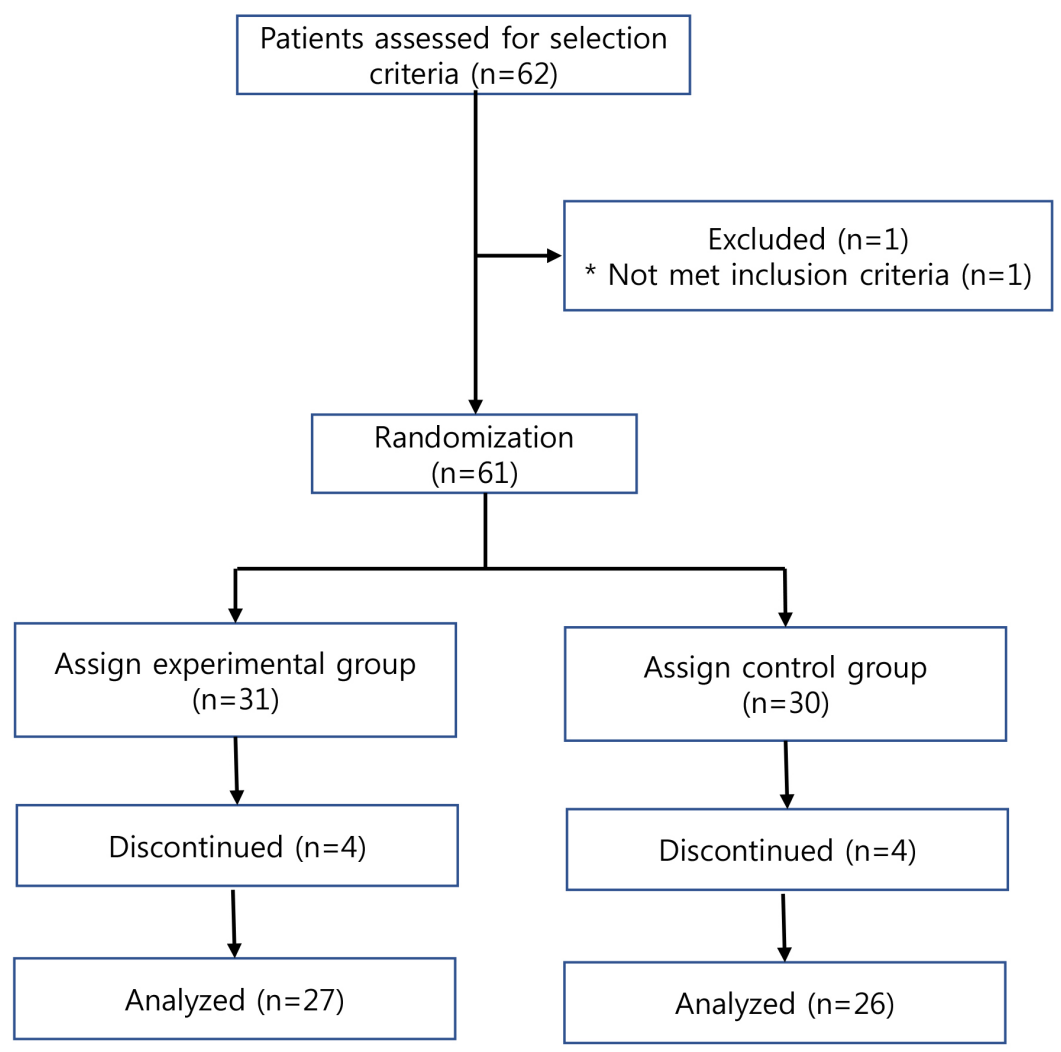

Figure 1. Flow diagram of the study .

palatal reflex has returned. ${ }^{2)}$ There is repeated puffing and swelling with $0.9 \%$ saline solution $30 \mathrm{cc}$ in an oral cavity while seating, rinsing the mouth, and spitting it out into an emesis basin for 1 minute. ${ }^{5,26)}$

Next, research assistants (experimental assistants and investigator) were trained. There were two experimental assistants, i.e. nurses who have worked in a hospital ward for thyroid cancer surgery patients for more than two years. A researcher provided 30 minutes training on how to gargle with a saline solution and how to provide a wet gauze and demonstrated saline gargling for one patient who had undergone thyroid cancer surgery. Each experimental assistant was asked to practice saline gargling for 2 different patients who had undergone thyroid cancer surgery.

As an investigator of the dependent variable, one of the nurses scheduled to begin employment at Kyungpook National University Hospital was selected and the researcher conducted a 1-hour training session on the dry mouth questionnaire, how to use oral spill pad, and how to measure sore throat NRS and sore throat OMDQ. To increase the measurement reliability of the dampness of oral spill pad, the consistency between the researcher and the investigator was checked by measuring the dampness of oral spill pads for three patients who had undergone thyroidectomy.

\section{2) Preliminary investigation}

At around $5 \mathrm{pm}$ the day before surgery, an investigator visited the subjects and asked them to fill out a questionnaire for general characteristics and characteristics related to surgery after thyroidectomy. On the day of surgery, when both the experimental group and the control group regained consciousness in a recovery room and entered a hospital room, the investigator visited the subjects and checked the subjective dry mouth questionnaire, the dampness of oral spill pad, and sore throat NRS as a preliminary survey.

\section{3) Experimental treatment}

An experiment assistant visited the subjects in the experimental 
group 1 hour after they entered a hospital room after surgery and trained them on the method and timing of saline gargling. The first saline gargling is performed 1 hour after arrival at a hospital room after surgery based on the prior study by Yoon and $\mathrm{Min}^{2)}$ to prevent the risk of aspiration after general anesthesia and then it is performed 3 hours and 5 hours after arrival at the hospital room after surgery, i.e. a total of 3 times. This is based on the results of prior studies ${ }^{27)}$ where gargling was conducted three times. If there is a dry mouth or a sore throat, it was instructed to additionally gargle with saline and also instructed not to use other gargle solutions other than the saline solution provided. The subjects were asked to record the time for additional gargling on a checklist.

At the same time, an experimental assistant visited the control group and applied the conventional method where a gauze was soaked in purified water and placed on the mouth. Eight sheets of $4 \times 4$ gauze were provided and it was instructed to put it on the mouth whenever the mouth was dry or the throat was soar by moistening the gauze with water from a water purifier. After the surgery, the experimental assistant visited patients 1, 3, and 5 hours after their arrival at the hospital room and asked them to wet their mouth with a gauze if their mouth was dry or their throat was sore and provided a checklist where they could record the time of gauze usage. The subjects were classified into group 1 (experimental group) and group 2 (control group) without knowing whether they were in the experimental group or the control group.

\section{4) Follow-up investigation}

The investigator measured the subjective dry mouth questionnaire, the dampness of the oral spill pad, and the sore throat NRS in the same manner as in the preliminary survey over a total of 3 times, i.e. 1 hour 30 minutes, 3 hours 30 minutes, 5 hours 30 minutes, after a subject arrived at a hospital room after surgery, From the results of a comparative study $y^{5)}$ of the effect of oral care using cold water gargling and wet gauze, the thirst level decreased 30 minutes after the experimental treatment, Therefore, in this study, the timing to measure the effect was set to 30 minutes after the experimental treatment. In addition, the subject was visited 24 hours after surgery to measure the OMDQ of sore throat. The investigator visited the subject 30 minutes after the end of the experimental treatment to make sure the investigator did not know what treatment was provided to the subject.

\section{Ethical Consideration}

For the ethical consideration of a subject, this study was conducted upon approval from the Institutional Review Board of Kyungpook National University Hospital in Daegu (IRB File No: 2017-12-014-002). After explaining the purpose, procedure, and duration of this study to the participants in this study, a written consent was received for their participation in this study. It was explained that the questionnaire data and computational medical record data collected in this study are anonymous and that they will not be disclosed or used except for the purpose of this study. It was explained that anonymity is guaranteed to protect the rights of a subject and that the subject can stop participation at any time if the subject wants. It was explained that all collected data would be stored in a locker-equipped storage box for 3 years and then destroyed using a document shredder. A small gift was presented to subjects in both the experimental group and the control group.

\section{Data Analysis}

The analysis was performed in the following manner using the SPSS/WIN. 20.0 program.

1) The general characteristics of a subject and the characteristics related to disease and surgery were analyzed using real numbers and percentages, and mean and standard deviation.

2) The general characteristics of the experimental group and the control group, the characteristics related to diseases and surgery, the subjective dry mouth before experimental treatment, the dampness of a oral spill pad, and the degree of sore throat were analyzed by using the $\chi^{2}$ test, Fisher's exact test, and independent t-test.

3) The difference in subjective dry mouth, dampness of oral spill pad, and degree of sore throat between the experimental group and the control group were analyzed by using the independent $\mathrm{t}$-test.

\section{RESULT}

\section{Homogeneity Verification Between the Experimental Group and the Control Group}

Prior to hypothesis verification, the normality of the measured variables in the experimental group and the control group was analyzed by using the Komogorov-Smirnov test and they all had normal distribution. There was no significant difference in general characteristics and the characteristics related to disease and surgery between the experimental group and the control group, so the two groups were found to 
be homogeneous. The preliminary subjective dry mouth score, the dampness of a oral spill pad, and the sore throat score, which are dependent variables in this study, were not significantly different between the experimental group and the control group, indicating that the two groups were homogeneous (Table 1).

\section{Effect of Saline Gargling}

The post average of the subjective dry mouth score was 8.17 for the experimental group and 9.97 for the control group. The difference between the post average and the pre average was -1.46 for the experimental group and 1.71 for the control group. There was a significant difference between the two groups, supporting Hypothesis $1(t=-2.19$, $p=.033$ ). When examining the change in the subjective dry mouth score over time, the experimental group's subjective dry mouth score was 9.15 and the control group's dry mouth score was 9.65 after 1 hour 30 minutes upon entering the ward, but there was no significant difference $(t=-0.44, p=.665)$. After 3 hours and 30 minutes, the subjective dry mouth score of the experimental group was 8.26 and that of the control group was 10.62. There was a significant difference between the two groups ( $\mathrm{t}=-2.23, p=.031$ ). After 5 hours and 30 minutes, the subjective dry mouth score of the experimental group was 7.11 and that of the control group was 9.65 , leading to a statistically significant difference $(\mathrm{t}=-2.09, p=.042)$ (Table 2) (Figure 2).

The post average of dampness of a oral spill pad was $24.43 \mathrm{~mm}$ for the experimental group and $22.22 \mathrm{~mm}$ for the control group and the difference between the post average and the pre average was $5.65 \mathrm{~mm}$ for the experimental group and $6.22 \mathrm{~mm}$ for the control group. There was no statistically significant difference between the two groups, so Hypothesis 2 was not supported $(t=-0.31, p=.757)$. When examining the dampness change of a oral spill pad in an oral cavity over time, the dampness of a oral spill pad for the experimental group was $23.85 \mathrm{~mm}$ and it was $19.65 \mathrm{~mm}$ for the control group $(\mathrm{t}=1.80, p=.078)$ after 1 hour and 30 minutes upon entering the ward. And the dampness of the experimental group was $22.89 \mathrm{~mm}$ and it was $22.15 \mathrm{~mm}$ for the

Table 1. Homogeneity Test for General Characteristics Outcome Variables between Experimental and Control Groups

$(N=53)$

\begin{tabular}{|c|c|c|c|c|c|}
\hline \multirow[t]{2}{*}{ Variables } & \multirow[t]{2}{*}{ Categories } & $\begin{array}{l}\text { Experimental group } \\
\qquad(n=27)\end{array}$ & $\begin{array}{l}\text { Control group } \\
\quad(n=26)\end{array}$ & \multirow[t]{2}{*}{$x^{2}$ or $t$} & \multirow[t]{2}{*}{$p$} \\
\hline & & $\mathrm{n}(\%)$ or $\mathrm{M} \pm \mathrm{SD}$ & $\mathrm{n}(\%)$ or $\mathrm{M} \pm \mathrm{SD}$ & & \\
\hline Age (year) & & $46.22 \pm 10.28$ & $50.31 \pm 11.53$ & -1.36 & $.179^{*}$ \\
\hline Marital status & $\begin{array}{l}\text { Married } \\
\text { Single }\end{array}$ & $\begin{array}{c}25(92.6) \\
2(7.4)\end{array}$ & $\begin{array}{c}25(96.2) \\
1(3.8)\end{array}$ & 0.32 & $>.999^{\dagger}$ \\
\hline Education & $\begin{array}{l}\leq \text { Middle school } \\
\text { High school } \\
\text { College or higher }\end{array}$ & $\begin{array}{r}3(11.1) \\
9(33.3) \\
15(55.6)\end{array}$ & $\begin{array}{r}5(19.2) \\
11(42.3) \\
10(38.5)\end{array}$ & 1.68 & $.431^{*}$ \\
\hline Monthly income (won) & $\begin{array}{l}\text { None } \\
1 \sim 2 \text { million } \\
>2.01 \text { million }\end{array}$ & $\begin{array}{r}11(40.7) \\
5(18.6) \\
11(40.7)\end{array}$ & $\begin{array}{r}18(69.2) \\
3(11.6) \\
5(19.2)\end{array}$ & 4.42 & $.110^{*}$ \\
\hline Job status & $\begin{array}{l}\text { Employed } \\
\text { Unemployed }\end{array}$ & $\begin{array}{l}16(59.3) \\
11(40.7)\end{array}$ & $\begin{array}{r}8(30.8) \\
18(69.2)\end{array}$ & 4.34 & $.054^{\dagger}$ \\
\hline Smoking & $\begin{array}{l}\text { Smoking } \\
\text { No smoking }\end{array}$ & $\begin{array}{c}2(7.4) \\
25(92.6)\end{array}$ & $\begin{array}{c}0(0.0) \\
26(100.0)\end{array}$ & 2.00 & $.491^{\dagger}$ \\
\hline Type of surgery & $\begin{array}{l}\text { Lt. lobectomy } \\
\text { Rt. lobectomy } \\
\text { Total thyroidectomy }\end{array}$ & $\begin{array}{r}9(33.3) \\
11(40.8) \\
7(25.9)\end{array}$ & $\begin{array}{l}8(30.8) \\
9(34.6) \\
9(34.6)\end{array}$ & 0.49 & $.783^{*}$ \\
\hline Signs of bleeding & $\begin{array}{l}\text { Dot hemorrhage } \\
\text { No bleeding }\end{array}$ & $\begin{array}{c}2(7.4) \\
25(92.6)\end{array}$ & $\begin{array}{r}3(11.5) \\
23(88.5)\end{array}$ & 0.26 & $.669^{\dagger}$ \\
\hline NPO time (minutes) & & $1143.00 \pm 127.44$ & $1161.85 \pm 137.79$ & -0.52 & .607 \\
\hline Operation time (minutes) & & $121.52 \pm 52.76$ & $112.69 \pm 25.32$ & 0.78 & .440 \\
\hline Anesthetic duration (minutes) & & $114.37 \pm 52.86$ & $104.62 \pm 24.30$ & 0.87 & .391 \\
\hline Subjective mouth dryness & & $9.63 \pm 5.98$ & $8.27 \pm 5.09$ & 0.89 & .378 \\
\hline Dampness of oral spill pads & & $18.78 \pm 5.97$ & $16.00 \pm 6.43$ & 1.63 & .109 \\
\hline Sore throat & & $7.78 \pm 2.21$ & $8.12 \pm 1.93$ & -0.59 & .556 \\
\hline
\end{tabular}

${ }^{*}$ Chi-square test; ${ }^{\dagger}$ Fisher's exact test; Lt. = left; Rt. = right; NPO= Nothing per oral. 
control group $(\mathrm{t}=0.31, p=.756)$ after 3 hours and 30 minutes and the dampness of the experimental group was $26.56 \mathrm{~mm}$ and it was $24.85 \mathrm{~mm}$ for the control group $(\mathrm{t}=0.75, p=.460)$ after 5 hours and 30 minutes. There was no significant difference between the two groups at all for all three measurement timings (Table 2) (Figure 2).

The post average of throat score was 4.54 for the experimental group and 5.72 for the control group and the difference between the post average and the pre average was -3.23 for the experimental group and -2.40 for the control group. When examining the change of the sore throat score over time, the experimental group's sore throat score was 5.78 and the control group's sore throat score was 6.38 after 1 hour and 30 minutes upon entering the ward and there was no statistically significant difference. After 3 hour and 30 minutes, the experimental group's sore throat score was 4.52 and that of the control group was 5.54, showing no statistically significant difference. However, after 5 hours and 30 minutes, the experimental group's sore throat score was 3.33 which was significantly lower than the control group's sore throat score of $5.23(\mathrm{t}=-3.75, p<.001)$, thus partially supporting Hypothesis

\section{3-1 (Table 2) (Figure 2).}

The overall sore throat score 24 hours after surgery was 12.63 for the experimental group and 17.38 for the control group. There was a significant difference between the two groups, thus supporting Hypothesis 3-2 $(\mathrm{t}=-2.65, p=.011)$. When examining the details of the overall sore throat, the overall health status was 2.89 for the experimental group and 4.08 for the control group, which indicated a significant difference $t$ between the two groups $(t=-2.02, p=.049)$, but the incidence of sore throat was 1.44 for the experimental group and 1.73 for the control group. Therefore, there was no statistically significant difference $(\mathrm{t}=-1.03, p=.360)$. The degree of limitation in daily activity due to sore throat was significantly different $(\mathrm{t}=-2.31, p=.025)$, i.e. 5.11 for the experimental group and 7.35 for the control group. The intensity of sore throat was 3.19 for the experimental group and 4.23 for the control group. which was significantly different $(\mathrm{t}=-2.03, p=.047)$ (Table 3$)$.

\section{DISCUSSION}

The discussion is based on the results of this study confirming the effects of saline gargling on postoperative dry mouth and sore throat with patients who had undergone thyroid cancer surgery. The subjective dry mouth score of the experimental group who performed saline gargling was significantly lower than that of the control group. There was no prior study where the same room temperature saline gargling was performed as done in this study, so there could not be direct comparison. However, when comparing the results to those of similar studies, Park and Shin ${ }^{28)}$ studied the effect of oral care using sterile saline solution on the occurrence of stomatitis with patients receiving chemotherapy. In that study, the dry mouth persisted at a low level for the experimental group who used the sterile saline solution. Meanwhile, the

Table 2. Differences in Outcome Variables between Groups

$(N=53)$

\begin{tabular}{|c|c|c|c|c|c|}
\hline \multirow[t]{2}{*}{ Variables } & \multirow[t]{2}{*}{ Categories } & $\begin{array}{l}\text { Experimental group } \\
\qquad(\mathrm{n}=27)\end{array}$ & $\begin{array}{l}\text { Control group } \\
\qquad(n=26)\end{array}$ & \multirow[t]{2}{*}{$\mathrm{t}$} & \multirow[t]{2}{*}{$p$} \\
\hline & & $\mathrm{M} \pm \mathrm{SD}$ & $\mathrm{M} \pm \mathrm{SD}$ & & \\
\hline \multirow{6}{*}{$\begin{array}{l}\text { Subjective mouth } \\
\text { dryness }\end{array}$} & Pre-op & $9.63 \pm 5.98$ & $8.27 \pm 5.09$ & 0.89 & .378 \\
\hline & Post-op average & $8.17 \pm 3.12$ & $9.97 \pm 3.46$ & -1.99 & .052 \\
\hline & Differences (post-pre) & $-1.46 \pm 5.89$ & $1.71 \pm 4.49$ & -2.19 & .033 \\
\hline & Post-op 1 hour \& 30 minutes & $9.15 \pm 3.81$ & $9.65 \pm 4.63$ & -0.44 & .665 \\
\hline & Post-op 3 hours \& 30 minutes & $8.26 \pm 3.42$ & $10.62 \pm 4.26$ & -2.23 & .031 \\
\hline & Post-op 5 hours \& 30 minutes & $7.11 \pm 4.30$ & $9.65 \pm 4.56$ & -2.09 & .042 \\
\hline \multirow{6}{*}{$\begin{array}{l}\text { Dampness of } \\
\text { oral spill pads }\end{array}$} & Pre-op & $18.78 \pm 5.97$ & $16.00 \pm 6.43$ & 1.63 & .109 \\
\hline & Post-op average & $24.43 \pm 7.34$ & $22.22 \pm 7.30$ & 1.10 & .276 \\
\hline & Differences (post-pre) & $5.65 \pm 5.86$ & $6.22 \pm 7.28$ & -0.31 & .757 \\
\hline & Post-op 1 hour \& 30 minutes & $23.85 \pm 8.62$ & $19.65 \pm 8.33$ & 1.80 & .078 \\
\hline & Post-op 3 hours \& 30 minutes & $22.89 \pm 8.10$ & $22.15 \pm 9.05$ & 0.31 & .756 \\
\hline & Post-op 5 hours \& 30 minutes & $26.56 \pm 8.07$ & $24.85 \pm 8.62$ & 0.75 & .460 \\
\hline \multirow[t]{6}{*}{ Sore throat } & Pre-op & $7.78 \pm 2.21$ & $8.12 \pm 1.93$ & -0.59 & .556 \\
\hline & Post-op average & $4.54 \pm 1.53$ & $5.72 \pm 2.00$ & -2.41 & .020 \\
\hline & Differences (post-pre) & $-3.23 \pm 1.80$ & $-2.40 \pm 2.08$ & -1.57 & .123 \\
\hline & Post-op 1 hour \& 30 minutes & $5.78 \pm 1.87$ & $6.38 \pm 2.26$ & -1.07 & .291 \\
\hline & Post-op 3 hours \& 30 minutes & $4.52 \pm 1.60$ & $5.54 \pm 2.32$ & -1.86 & .070 \\
\hline & Post-op 5 hours \& 30 minutes & $3.33 \pm 1.66$ & $5.23 \pm 2.01$ & -3.75 & $<.001$ \\
\hline
\end{tabular}

pre-op $=$ preoperative; post-op $=$ postoperative . 


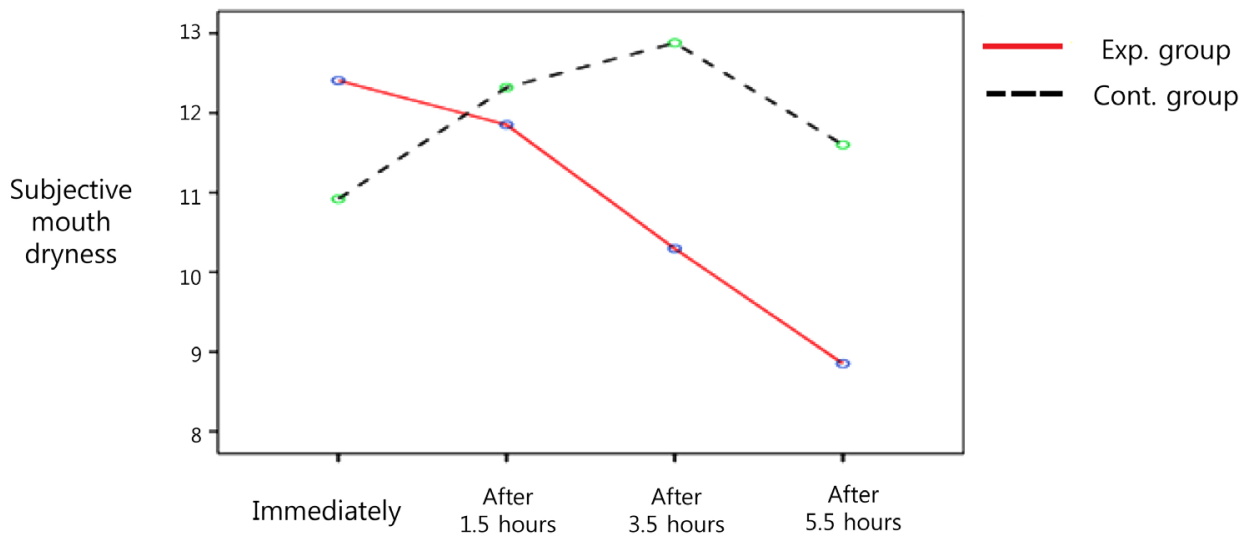

Hours after coming to ward from OR

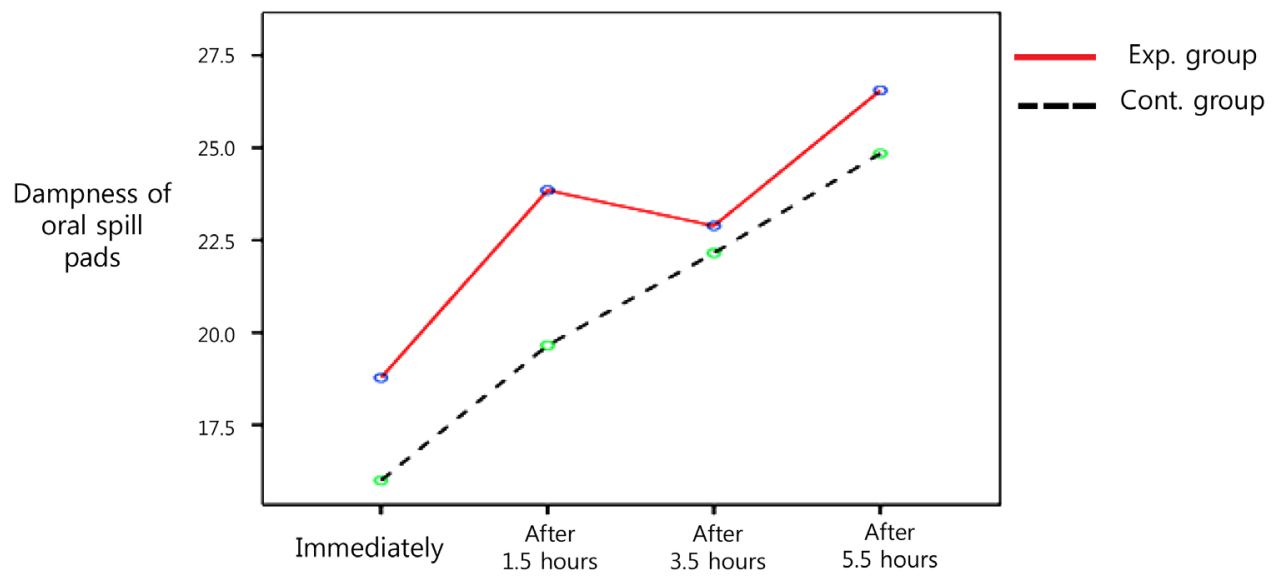

Hours after coming to ward from OR

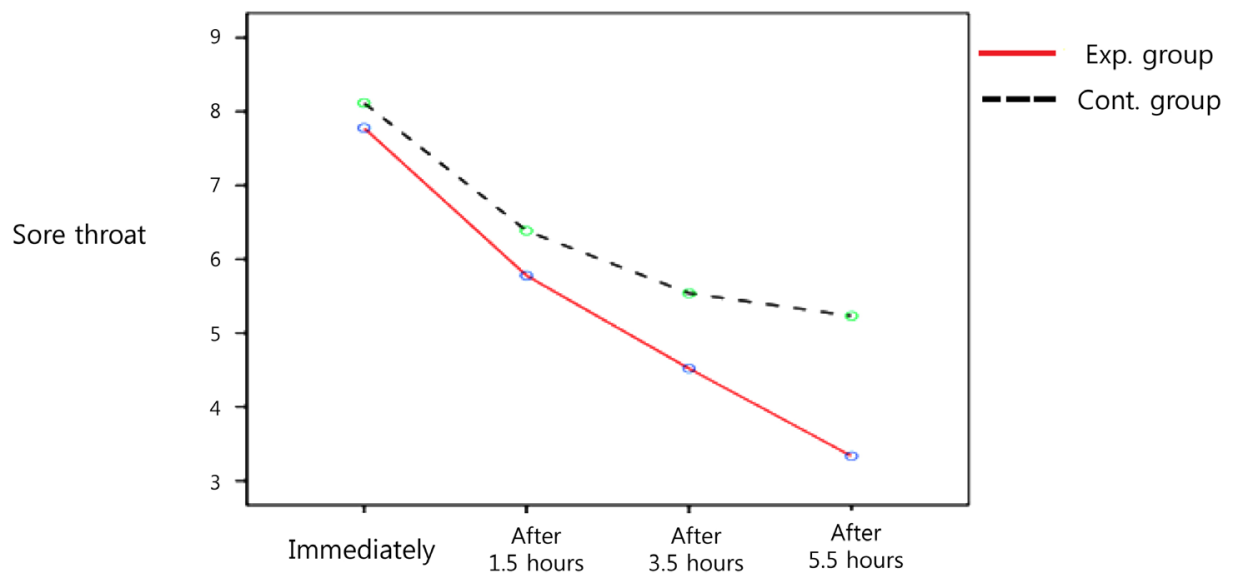

Hours after coming to ward from OR

Figure 2. Differences in subjective mouth dryness, dampness of oral spill pads and sore throat over time between experimental and control groups. 
Table 3. Differences in Overall Mouth Dryness by Oral Mucositis Daily Questionnaire between Groups

$(N=53)$

\begin{tabular}{|c|c|c|c|c|}
\hline \multirow[t]{2}{*}{ Variables } & $\begin{array}{l}\text { Experimental group } \\
\qquad(n=27)\end{array}$ & $\begin{array}{l}\text { Control group } \\
\qquad(n=26)\end{array}$ & \multirow[t]{2}{*}{$\mathrm{t}$} & \multirow[t]{2}{*}{$p$} \\
\hline & $\mathrm{M} \pm \mathrm{SD}$ & $\mathrm{M} \pm \mathrm{SD}$ & & \\
\hline Total score & $12.63 \pm 5.83$ & $17.38 \pm 7.20$ & -2.65 & .011 \\
\hline General physical condition & $2.89 \pm 1.97$ & $4.08 \pm 2.31$ & -2.02 & .049 \\
\hline Occurrence frequency of sore throat & $1.44 \pm 0.93$ & $1.73 \pm 1.07$ & -1.03 & .306 \\
\hline Degree of limitation in daily activity due to sore throat & $5.11 \pm 3.52$ & $7.35 \pm 3.53$ & -2.31 & .025 \\
\hline Intensity of sore throat & $3.19 \pm 1.73$ & $4.23 \pm 2.01$ & -2.03 & .047 \\
\hline
\end{tabular}

dry mouth became severe and then gradually decreased over time for the control group, which was similar to the results of this study. A study by Cho et al. ${ }^{29)}$ on the effect of providing a frozen gauze using a saline solution on the thirst level and oral conditions of the laparoscopic cholecystectomy patients also showed that a saline solution frozen gauze was more effective in relieving a parched mouth than providing ice, which was similar to the results of this study.

Surgery patients and fasting patients complain of dry mouth a lot and continuous dry mouth can increase patient discomfort and cause nutritional problems. Since this study showed that room temperature saline gargling relieves dry mouth after surgery, it is necessary to continuously apply saline gargling to surgery and fasting patients to reduce dry mouth. It is thought that saline gargling is an oral care method that can be comfortably applied to patients because it is simple to prepare, inexpensive, and easy to apply, and there is little concern about side effects. In clinical practice, applying a gauze soaked in purified water to the lips has a limited effect only on the area where the gauze touches. However, as saline gargling can rinse the entire mouth evenly, it has a greater effect on alleviating dry mouth.

In this study, to measure dry mouth more accurately, there were two kinds of measurements. The objective dry mouth level was measured by dampness of a oral spill pad and the subjective dry mouth was measured by questionnaire. In this study, the objective dry mouth did not show any significant difference between the experimental group and the control group, but the study by $\mathrm{Cho}$ and $\mathrm{Cho}^{30)}$ showed that saline was found to be more effective in reducing dry mouth than an aroma solution when comparing oral spill pads to measure dryness when conducting mouthwash for nursing college students. In the study by Kim and Park, ${ }^{19)}$ the amount of salivation measured by a oral spill pad on the 1st and 2nd day after surgery was higher with the experimental group who rinsed the mouth with water and conducted the salivation stimulation exercise, so the salivation stimulation exercise increased the salivation among the patients who fasted after surgery, thus relieving dry mouth.

Although the subjects in the experimental group participating in this study verbally expressed that their dry mouth improved significantly after gargling with a saline solution, the dampness of a oral spill pad did not show a significant difference between the experimental group and the control group. In the experimental group, most of the additional gargling, other than regular gargling, was performed 30 minutes before the measurement time of a oral spill pad. However, in the control group, a wet gauze was applied just before the measurement time because the application time of wet gauze was not controlled. And the average number of gargling was 3.14 times for the experimental group, but the number of additional gauze application was 8.72 times for the control group. These two variables might have an effect on the study results. Therefore, in future studies, it is necessary to measure the dampness of a oral spill pad by controlling the application time of gargling and wet gauze for each group. In most studies, only subjective measurement is performed when measuring dry mouth after surgery. To measure the degree of dry mouth more accurately, it is necessary to perform repeated studies using a oral spill pad which is an objective data collection method as in this study.

Next, there was no significant difference in sore throat scores between the experimental group and the control group immediately after surgery. This is similar to the results of Yoon and Min's's) study where there was no significant difference between the two groups due to decreased sore throat in both the cold water gargling experimental group and the wet gauze control group. Oh and Sok ${ }^{27)}$ measured the degree of sore throat among the aroma solution, cold water gargling, and wet gauze groups. As a result, the sore throat decreased every 30 minutes after treatment compared to preliminary examination and the sore throat was significantly reduced in the aroma solution group after 90 minutes, but there was no significant difference at other timings, which 
was similar to the results of this study.

There was no significant difference in sore throat between the experimental group and the control group. It seems to be that the residual effect of general anesthetic remaining after anesthesia and the effect of ketocin, i.e. a pain reliever prescribed on the day of surgery, made both the experimental group and the control group less aware of pain ${ }^{4)}$ and also sore throat. As time goes by, the effect of the anesthesia dissipated and the sore throat was actually felt. Then gargling was performed to the larynx more deeply and it was found that the sore throat of the experimental group was significantly lower than that of the control group at timing 3 in the post examination, i.e. 5 hours and 30 minutes after surgery. Because gargling may not work properly when it is done in a lying state after surgery, it is necessary to study whether or not gargling can be performed in a half seated position when there is no risk of aspiration in order to increase the effect of reducing sore throat. In addition, because Pro re nata (PRN) analgesics administered when necessary to manage pain at the location on the body where surgery was conducted may affect sore throat, it is necessary to control PRN analgesics in the future studies.

The total sore throat OMDQ measured 24 hours after surgery was found to be significantly lower in the experimental group who had engaged in saline gargling. When looking at the details, the overall health status, the degree of limitation in daily activity due to sore throat, and the intensity of sore throat were lower in the experimental group, but there was no significant difference in the incidence of sore throat between the two groups. In most studies, ${ }^{2,14)}$ sore throat was measured for a period from 90 minutes to 8 hours after surgery. However, in this study, the sore throat was measured until 24 hours after surgery based on the fact that the sore throat lasts up to $24 \sim 48$ hours ${ }^{3)}$ due to the occurrence of local ischemia, mucosal damage and swelling of the airway mucosa caused by airway intubation. As a result of this study, it was found that saline gargling was effective in reducing sore throat for up to 24 hours after surgery. In this study, it was verified that saline solution gargling can help the alleviation of sore throat and oral discomfort 24 hours after surgery, so it is necessary to provide it as a nursing intervention on the first day after surgery.

The results of this study showed that saline gargling effectively alleviated the subjective dry mouth, sore throat 5 hours after surgery and sore throat 24 hours after surgery for patients after thyroidectomy, and thus its effectiveness was verified. Saline gargling is economical compared to other interventional therapies, is easily applicable by medical personnel, and has advantages in that a patient can easily conduct it alone. Therefore, it can be used as an effective nursing intervention in clinical practice to alleviate dry mouth and sore throat for patients who are fasting and who have undergone gastrointestinal surgery as well as thyroidectomy.

\section{CONCLUSION}

This study showed that saline gargling was effective in terms of relieving subjective dry mouth and sore throat after 5 hours 30 minutes and 24 hours after surgery, but there was no significant difference between the objective dry mouth measured by the dampness of a oral spill pad and sore throat immediately after surgery. Therefore, it is expected that saline gargling can be used as a nursing intervention for patients who have undergone thyroidectomy in order to relieve the symptoms of subjective dry mouth and relieve discomfort caused by sore throat that lasts $1 \sim 2$ days after surgery.

Based on the above research results, the followings are suggested. First, in this study, it is necessary to unify the intervention between the experimental group and the control group immediately before the measurement of the dampness of a oral spill pad and to control PRN painkillers in future studies. Second, it is necessary to conduct repeated studies that increase the number of subjects in order to further substantiate the effects regarding dry mouth and sore throat.

\section{ORCID}

Kim, Do Hui orcid.org/0000-0002-4448-2473

Park, Jeong Sook orcid.org/0000-0001-8356-6998

\section{REFERENCES}

1. National Cancer Information Center. National cancer registration statistics. Available from:

https:/www.cancer.go.kr/layl/S1T639C641/contents.do Accessed December 30, 2019

2. Yoon SY, Min HS. The effects of cold water gargling on thirst, oral cavity condition, and sore throat in orthopedics surgery patients. Korean J Rehabil Nurs. 2011;14:136-44.

3. Biro P, Seifert B, Pasch T. Complaints of sore throat after tracheal intubation: prospective evaluation. Eur J Anaesthesiol. 2005;22:307-11.

4. Maruyama K, Yamada T, Hara K. Effect of clonidine premedication on postoperative sore throat and hoarseness after total intravenous anes- 
thesia. J Anesth. 2006;20:327-30

5. Lee IS, Shim MS, Na EH, Kang JY, Kim JH, Hwang MY, et al. . The comparison of thirst care intervention between the wet gauze and the cold water gargling to the nasal surgery patients. Clin Nurs Res. 2006; 11:21-33.

6. Hisham AN, Roshilla H, Amri N, Aina EN. Post-thyroidectomy sore throat following endotracheal intubation. ANZ J Surg. 2001;71:669-71.

7. Lehmann M, Monte K, Barach P, Kindler CH. Postoperative patient complaints: a prospective interview study of 12,276 patients. J Clin Anesth. 2010;22L:13-21.

8. Christensen AM, Willemoes-Larsen H, Lundby L \& Jakobsen KB. Postoperative throat complaints after tracheal intubation. Br J Anaesth. 1994;73:786-7.

9. Sanou J, Ilboudo D, Rouamba A, Traore O. Sore throat after tracheal intubation. Cah Anesthesiol. 1996;44:203-6.

10. Cassolato SF, Turnbull RS. Xerostomia: clinical aspects and treatment. Gerodontology, 2003;20:64-77.

11. Darby ML, Walsh MM, Bowen DM. Dental Hygiene. St. Louis, MO: Elsevier/Saunders; 2012.p. 78-85.

12. Sakai M, Shimbo T, Omata K, Takahashi Y, Satomura K, Kitamura T, et al. Cost-effectiveness of gargling for the prevention of upper respiratory tract infections. BMC Health Serv Res. 2008;8:258.

13. Kim HJ. The effects of cold water gargling on postoperative nausea and thirst in thyroidectomy patients [master's thesis]. Busan: Dong-Eui Univ:; 2013.

14. Chung SH. The effects of an essential oil mouthrinse on oral health in the community indwelling elderly. J Korean Acad Nurs. 2006;36:84-93.

15. O'Connor A. The claim: gargling with salt water can ease cold symptoms. The New York Times, Late Edition (East Coast), 2010 Sep 27.

16. Jung SN. The effects of the normal saline and chlorhexidine on oral care hygiene of patients on intensive care unit [master's thesis]. Seoul: Dankook Univ.; 2005.

17. Choi SH, Kim YK. The effect of oral care with normal saline on oral state of patients in intensive care unit. J Korean Acad Adult Nurs. 2004;16:452-9.

18. Urbaniak GC, Plous S. Research randomizer (version 4.0)[computer software]. Retrieved on March 1, 2018.

19. Thomson WM, Chalmers JM, Spencer AJ, Williams SM. The Xerostomia Inventory: a multi-item approach to measuring dry mouth. Community Dent Health. 1999;16:12-7.

20. Fox PC, Busch KA, Baum BJ. Subjective reports of xerostomia and objective measures of salivary gland performance. J Am Dent Assoc. 1987;115:581-4.

21. Yarbro CH, Wujcik D, Gobel BH. Cancer Symptom Management. Burlington, MA: Jones \& Bartlett Learning; 2014.

22. Kim AN, Park JS. The effect of a salivation stimulation method on xerostomia in colon cancer patients after surgery. Asian Oncol Nurs. 2016;16:75-84.

23. Chu HR, Kim CH, Lee JS, Park SK, Koh ES, Rho YS. Diagnosis of salivary gland function using oral Schirmer test. Korean J Otorhinolaryngol-Head Neck Surg. 2008;51:153-6.

24. Bellm LA, Cunningham G, Durnell L, Eilers J, Epstein JB, Fleming T, et al. Defining clinically meaningful outcomes in the evaluation of new treatments for oral mucositis: oral mucositis patient provider advisory board. Cancer Invest. 2002;20:793-800.

25. Choi SE, Kim HS. Reliability and validity of patient self-reported daily questionnaire on oral mucositis in acute leukemic patients under chemotherapy. J Korean Biol Nurs Sci. 2010;12:148-56.

26. Song JA, Hur MH. Effects of A-solution on halitosis and oral status in preoperative NPO patients. J Korean Acad Nurs. 2012;42:405-13.

27. Oh KE, Sok SH. Effects of aroma gargling therapy on thirst, halitosis and pharyngitis of patients after spine surgery [master's thesis]. Kyung Hee Univ:; 2015.

28. Park HJ, Shin HS. The effects of mouth care with sterile normal saline on chemotherapy-induced stomatits. J Nurs Acad Soc. 1995;25:5-16.

29. Cho EA, Kim KH, Park JY. Effects of frozen gauze with normal saline and ice on thirst and oral condition of laparoscopic cholecystectomy patients: pilot study. J Korean Acad Nurs. 2010;40:714-23.

30. Cho MK, Cho YH. Comparisons of the effects of a-solution and $0.9 \%$ normal saline oral gargling on xerostomia, halitosis, and salivary $\mathrm{pH}$ in nursing students. J Korean Biol Nurs Sci. 2014;16:141-9. 